\title{
Clinical profile of childhood Guillain-Barre Syndrome
}

\author{
Meshram R. $\mathrm{M}^{1}$, Bokade C. $\mathrm{M}^{2}$, Merchant $\mathrm{S}^{3}$, Abhisheik $\mathrm{S}^{4}$, Agrawal H5 , Dhakne $\mathrm{S}^{6}$.
}

${ }^{1}$ Dr Rajkumar M. Meshram, Associate Professor, ${ }^{2}$ Dr C. M. Bokade, Professor \& Head, ${ }^{3}$ Dr Saira Merchant, Professor, ${ }^{4}$ Dr S. Abhisheik, Assistant Professor, ${ }^{5}$ Dr Hina Agrawal, PG Student, ${ }^{6}$ Dr Samadhan Dhakne, PG Student. All are affiliated Department of Paediatrics, Government Medical College, Nagpur, Maharashtra (India).

Address for Correspondence: Dr Rajkumar M. Meshram, Associate Professor, Department of Paediatrics Government Medical College, Nagpur, Maharashtra (India). Email: dr_rajmeshram@rediffmail.com

\begin{abstract}
Objective: Recognizing the clinical presentation of Guillain-Barre syndrome in children. Design: Retrospective observational study. Setting: Pediatric wards and Paediatric Intensive Care Unit. Method: A medical record files of 52 patients of GBS, between the periods of March 2011 to February 2016 were recovered from Medical Record and Statistics Section of institute. Files were analyzed for demographic data, clinical features, co-morbid conditions, investigations, electrophysiological data, mode and result of treatment and data was analyzed. Result: In our series males are outnumber to female and most of the patients in age group 6-12 years, 48\% were belongs to lower socioeconomic status. In 53.8\% patients antecedents were present at the beginning of clinical picture and upper respiratory tract infection $(28.84 \%) \&$ diarrohea (19.23\%) was noted with predominant occurrence in monsoon season (52\%). Bilateral lower limb weakness was noted in all patients and in $61.9 \%$ patients were common complaint pain in lower limb. Cranial nerve involvement was evident in $28.85 \%$ and bulbar involvement was commonest followed by facial nerve. A $23.07 \%$ patients were presented with respiratory involvement, 9 of them $(15.38 \%)$ were needed assisted ventilation. Dysautonomic sign/symptoms were present in $26.92 \%$ with $73.33 \%$ had demyelinating pattern of neuropathy and $9.6 \%$ mortality. Conclusion: The clinical characteristics of GBS in children are not consistent and differ from geographical area and racial diversity.
\end{abstract}

Key Words: Guillain Barre Syndrome, Antecedent Factors, Acute Demyelinating Polyneuropathy, Clinical Profile.

\section{Introduction}

Since poliomyelitis has been nearly been eliminated, the Guillain-Barry Syndrome (GBS) is currently the most frequent cause of acute flaccid paralysis worldwide and constitutes one of the serious emergency in neurology [1]. The earliest description of GBS dates to $19^{\text {th }}$ century regarding an afebrile generalized paralysis by Wardrop and Ollivier in 1834. Other important landmarks are Landry's report in 1859 about an acute, ascending, predominantly motor paralysis with respiratory failure, leading to death [2] and Osler's (1892) description of afebrile polyneuritis [3]. Guillain, Barre and Strohl (1916) described a benign polyneuritis with albumin-cytological dissociation in the cerebrospinal fluid [4] and the first report regarding pathology of GBS was by Haymaker and Kernohan in 1949 who reported that edema of the nerve roots was an

Manuscript received: $15^{\text {th }}$ May 2016

Reviewed: $27^{\text {th }}$ May 2016

Author Corrected; $11^{\text {th }}$ June 2016

Accepted for Publication: $25^{\text {th }}$ June 2016 important change in the early stages of the disease [5]. Asbury, Arnasonand and Adams (1969) established that the essential lesion is due to perivascular mononuclear inflammatory infiltration of the roots and nerves [6]. Global annual incidence is reported to be $0.6-2.4$ cases per lakh population per year [7, 8]. It increases in incidence with age and there is a small predominance of male [9]. In North America and Europe, typical patients with GBS usually have the demyelinating variant termed acute inflammatory demyelinating polyneuropathy (AIDP) accounts for up to $90 \%$ of cases [10 ], whereas in China, Japan, Bangladesh and Mexico, the frequency of axonal Guillain-Barre syndrome ranges from $30-65 \%$ and the frequency of demyelinating GBS ranges from 22 to $46 \%$ [11,12]. There is a paucity of comparable data from India.

Etiology of GBS is not completely understood but believes to be due to autoimmuno cause where majority 
of cases are triggered by infection stimulating antiganglioside antibody production. Two third of cases are preceded by symptoms of upper respiratory tract infection or diarrohea. The most frequent identified infectious agent associated with subsequent development of Guillain-Barre syndrome is Campylobacter jejuni, Cytomegalovirus, Epstein-Barr virus, Varicella-Zoster virus and mycoplasma pneumonia [1].

Administration of outmoded antirabies vaccine A/New Jersey (swine flu) influenza vaccine given in 1976 was associated with slight increase in GBS incidence. New influenza vaccine appears to confer risk of $<1$ per million and are relatively safe $[13,14]$. Clinical features of Guillain-Barre syndrome include parasthesia, numbness, and pain in limbs, progressive bilateral and relatively symmetric weakness of limbs, usually ascending type with generalized hyporeflexia or areflexia.

Lower limbs are affected more than upper limbs. Sensory involvement, cranial nerve involvement and autonomic dysfunction including fluctuating blood pressure, tachyarrhythmia, bradyarrhythmia, abnormal sweating are also common in childhood GBS. Respiratory failure requiring mechanical ventilation is a serious short term complication and leading cause of mortality in paediatric population. Seasonal variation have also been noted in occurrence of GBS cases [15]. A common misconception is that the Guillain-Barre syndrome has good prognosis-but up to $20 \%$ of patients remain severely disabled and approximately $5 \%$ die, despite immunotherapy [16 ]

\section{Material \& Methods}

This series of patient with Guillain-Barre syndrome were retrospectively studied at one of the largest tertiary care \& referral hospital that provide care to underprivileged, socioeconomically deprived population of central India from March 2011 to February 2016. The medical records were recovered by the medical case files from the Medical Record Section and Statistical Service of the institute and the information was collected to conform to a preestablished protocol after approval from institutional ethical committee. The medical records were analyzed for the demographic data, clinical features, co-morbid conditions, investigations, electrophysiological data, mode and result of treatment. We classified our patients according to Modified Kuppuswamy's Socioeconomic Scale into Lower, middle and upper socioeconomic class [17]. Medical Research Council (MRC) sum score was used for evaluating the muscle strength from 0 to 5 in proximal and distal muscle in upper and lower limb bilaterally. Cranial nerve involvement was noted along with respiratory muscle weakness which was assessed by need of mechanical ventilation and oxygen administration. Sensory system and autonomic abnormalities were also analyzed.

Statistical analyses: The data regarding the numerical variables were summarized through average, medium and deviation pattern. Categorical data were summarized and presented inform of frequency. The frequencies comparison between the two sexes was accomplished by the binomial test. The $\mathrm{P}<0.05$ was considered significant.

\section{Results}

Total 52 patients were enrolled from March 2011 to February 2016, 27 (52\%) male and 25 (48\%) female, without significant difference between two sexes. The age of onset varies from 9 months to 12 years with a mean age 5.76 years. A $25(48 \%)$ patients were belongs to lower socioeconomic status while $20(38.46 \%)$ were middle class and 7 (13.40\%) from upper socioeconomic class. The presence of antecedents at the beginning of the clinical picture was referred in 28 $(53.85 \%)$ patients (Table 1); among them, the most frequent was upper respiratory tract infection $(28.84 \%)$ followed by diarrohea. Time between the antecedents and the beginning of symptoms varied from 2 to 60 days.

Table-1: Distribution of antecedents at the beginning of the clinical picture.

\begin{tabular}{|l|c|c|}
\hline Antecedents factor & Frequency & $\mathbf{\%}$ \\
\hline Absent & 24 & 46.15 \\
\hline URTI & 15 & 28.84 \\
\hline Diarrohea & 10 & 19.23 \\
\hline Vaccine & 1 & 1.92 \\
\hline Hepatitis & 2 & 3.85 \\
\hline Total & 52 & 100 \\
\hline
\end{tabular}


Seasonal occurrence in GBS is prominent in monsoon (June to September) 27 (51.92\%), followed by summer ( March to May) 10 (19.23\%), post monsoon (October, November) 8 (15.39\%) and winter (December to February) 7 (13.46 \%).

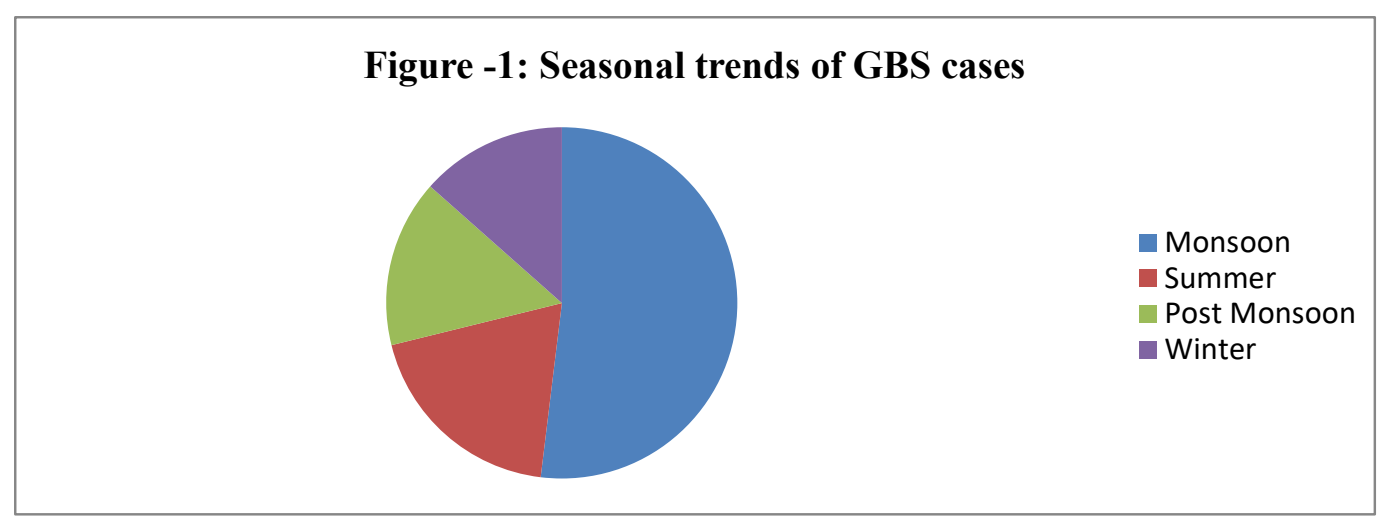

Figure -1: Seasonal trends of GBS cases

In relation to clinical presentation all patients presented with bilateral lower limb weakness. In $2(3.85 \%)$ patient fever was reported at the beginning of the symptoms. The clinical course was increased in $50(96.15 \%)$ of the patient. Involvement of cranial nerve was present in 15 (28.85\%) and details of affected cranial nerve shows in these patients are shown in Table 2.

Table-2: Cranial Nerve Involvement.

\begin{tabular}{|l|c|c|}
\hline Cranial Nerve & Frequency & $\mathbf{\%}$ \\
\hline III & 2 & 13.33 \\
\hline VI & 1 & 6.67 \\
\hline VII & 5 & 33.33 \\
\hline IX, X & 7 & 46.67 \\
\hline Total & 15 & 100 \\
\hline
\end{tabular}

A $12(23.07 \%)$ patient presented with respiratory involvement, 9 of them (15.38\%) needed assisted ventilation. In 12 patient $(23.07 \%)$, there were one or more signs/symptoms of sphincter disturbances (Figure 2); pain was present in 21 (40.38\%), involving more frequently the legs followed by arms, lumber and cervical area (Table 3); Dysautonomic signs and symptoms (Table 4) were disclosed in 14 (26.92\%) patients. All patients had decreased or abolished deep reflex response of the legs and arms.

Table-3: Distribution of Pain in location.

\begin{tabular}{|l|c|c|}
\hline Site & $\mathbf{n}$ & $\mathbf{\%}$ \\
\hline Inferior limb & 13 & 61.91 \\
\hline Superior limb & 4 & 19.05 \\
\hline Lumbar & 2 & 9.52 \\
\hline Cervical & 1 & 4.76 \\
\hline Abdominal & 1 & 4.76 \\
\hline Total & 21 & 100 \\
\hline
\end{tabular}

Table-4: Dysautonomic Sign and symptoms

\begin{tabular}{|l|c|c|}
\hline Dysautonomic sign & $\mathbf{n}$ & $\mathbf{\%}$ \\
\hline Increase BP & 8 & 57.14 \\
\hline Hyperemia & 3 & 21.43 \\
\hline Tachycardia & 2 & 14.29 \\
\hline Hypothermia & 1 & 7.14 \\
\hline Total & $\mathbf{1 4}$ & $\mathbf{1 0 0}$ \\
\hline
\end{tabular}


All patients underwent lumber puncture in order to analyze cell count and the total protein. Hypercytosis was defined as WBC count $>4$ cell/cumm and protein concentration $>40 \mathrm{mg} / \mathrm{dl}$. The result of CSF analysis is exposed in Table 5 .

Table-5: Distribution of patient according to CSF cell \& total protein concentration.

\begin{tabular}{|l|c|c|c|c|c|}
\hline Cells & $\mathbf{N}$ & $\mathbf{\%}$ & Total protein & $\mathbf{N}$ & $\mathbf{\%}$ \\
\hline Normal & 37 & 71.15 & Normal & 0 & 0 \\
\hline Mild to moderate & 15 & 28.85 & Mild to moderate & 45 & 86.54 \\
\hline High/ Intense & 0 & 0 & High & 7 & 13.46 \\
\hline Total & 52 & 100 & total & 52 & 100 \\
\hline
\end{tabular}

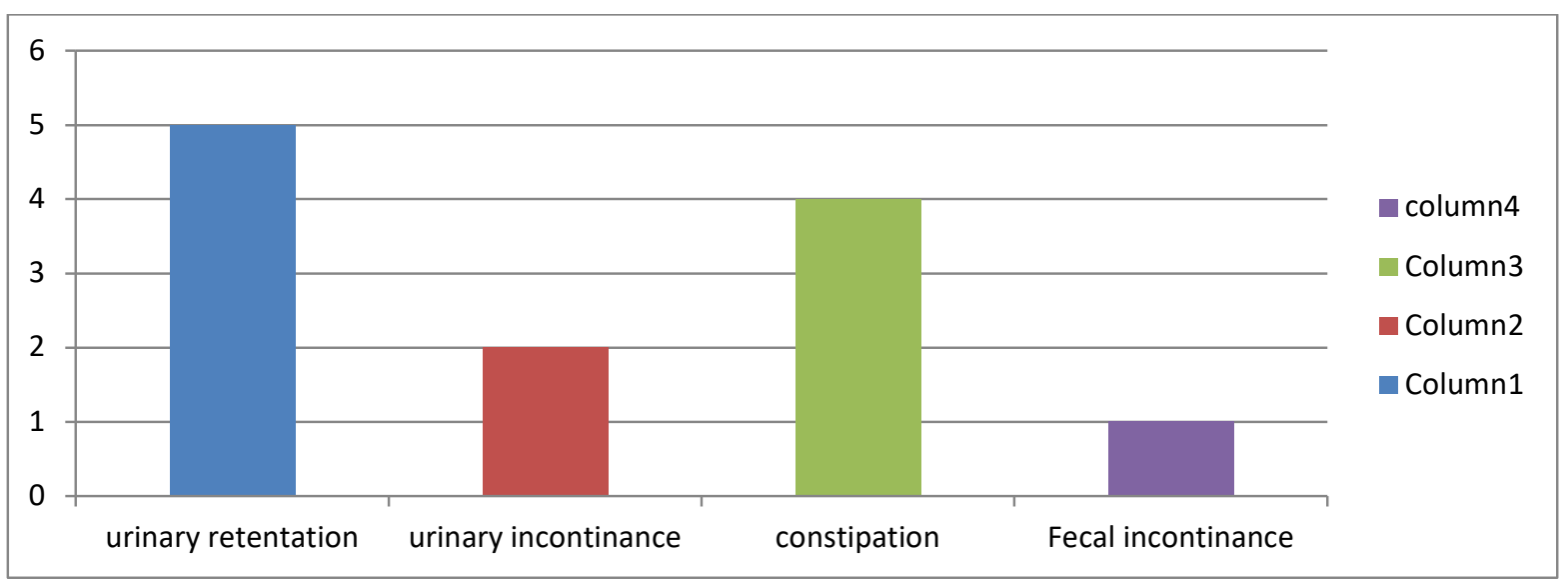

Figure-2: Distribution of sign and symptoms of sphincter disturbances.

In 15 patient, electromyography and nerve conduction was performed that disclosed a demyelination pattern in $11(73.33 \%)$, a purely motor axonal in $3(20 \%)$ and a mixed type in $1(6.67 \%)$. All patients with demyelinating pattern had complete recovery. Total $5(9.61 \%)$ patient died in study group.

\section{Discussion}

Guillain-Barre syndrome was defined more than a century back but the clinical characteristics in children from different studies are not consistent, which might be due to geographical and racialdiversity, even the clinical characteristics in pediatric GBS differ from that in adult ones $[8,18]$. Hence it is imperative that data from pediatric cohort is separately evaluated. We bring a result of retrospectively collected data on clinical profile in Indian children. In our study males are outnumbered to female as it has been shown in various studies that there is a small predominance of male in occurrence of GBS cases[1,8,15,18]. Age is an important factor determining outcome and prognosis in children and is said to be favorable as compared to adults [8]. In childhood it is usually occurs after the age of 3 years [19]. In this series, the age varied from 9 months to 12 years and more commonly in the age group 6 years to 12 years, similar distribution of age was reported by $\mathrm{Wu} X$ et al [20] in their study. Socioeconomically most of our patients (48\%) were from lower class and $38.46 \%$ were from middle class. Such a high occurrence of GBS in our series might be because of our institute served to socioeconomically deprived population and might be the incidence of infections are more common in such socioeconomic class. There is paucity of data related to incidence of GBS and socioeconomic condition. Seasonal or monthly variation in the occurrence of GBS is noted in our study. In our study most of the patients presented to us in monsoon (June to September) followed by summer. Similar types of observations were reported by Sharma $\mathrm{G}$ et al and Mathew $\mathrm{T}$ et al $[15,21]$. The reason for this disparity remains unclear and still need further elucidation. It is noteworthy that the microbiological data was not available due to the retrospective nature of our study. Whether the seasonal variation correlates to different pathogens, which might be asymptomatic or lead to non specific symptoms, warrants further elucidation. A previous infection should always be searched particularly when trying to define the presence 
of some agents more frequently related to GBS. In $53.85 \%$ of patients of this series there was a report of a clinical events before the first symptoms of GBS. Among these events the most frequent was unspecific upper respiratory tract infection followed by diarrohea. Most of the studies in literature noted that antecedent's factors associated with occurrence of GBS and most commonly URTI and diarrohea $[1,7,20,22]$.

In relation with clinical presentation, the main feature is progressive bilateral and relatively symmetric weakness that progresses over a period of 12 hours to 28 days before a plateau is reached. Patients typically have generalized hyporeflexia or areflexia. The involvement of cranial nerves occurred in $28.85 \%$ patients. IX, X nerve being most commonly attacked; that fact has not different to that found in literature [20]. The respiratory involvement $(23.07 \%)$, as well as mechanical ventilation need $(15.38 \%)$ were similar that reported by van der Linden et al [19].

Pain was present in $40.38 \%$, more frequently in the inferior limbs and it was an important cause of irritability in smaller children to accomplish the neurological examination, delaying in the diagnosis in some cases. van der Linden had reported $62.3 \%$ of patients were presented with pain in their study. Our reported incidence of pain might be lower than actual proportion in that some children could not describe their symptoms.

Dysautonomic sign and symptoms were present in $26.92 \%$ of the patients, the most frequent changes being sphincter disturbances and the systemic arterial hypertension. Similar types of autonomic disturbances were reported by Chatterjee et al and van den Linden et al $[18,19]$. But tachycardia is most frequently reported in literature, which was not evident in this series. That fact may be due to greater need of monitoring. In few patients may develop severe bradyarrthymias which are recognized cause of infrequent death from the syndrome [9].

In this series 5 patients died giving a mortality of $9.6 \%$. Among that all patients were presented with respiratory involvement, bulbur involvement and needed mechanical ventilation and died inspite of appropriate management. Our results were comparable with various studies $[7,8]$. CSF examination was performed in all patients and CSF protein was increased in all patients. Abnormal rise of CSF protein in GBS may be due to inflammatory reaction in the choroid plexus or disturbance in process of transport or breakdown of the blood CSF barrier [7]. Only 15 patients were subjected to electromyography and nerve conduction study. In $73.33 \%$ presented a demyelinating pattern, $20 \%$ with an axonal pattern and $6.67 \%$ with a mixed pattern. Our results were comparable with van der Linden et al, $\mathrm{Wu}$ $\mathrm{X}$ et al and Sudulagunta et al.

\section{Conclusion}

The clinical characteristics of GBS in children are not consistent and differ from geographical area and racial diversity. Males are outnumber to female with more than $50 \%$ patients had antecedents at the beginning of clinical picture and most commonly occurred in monsoon season. Pain was the common associate complaint with bilateral ascending lower limb weakness. Bulbular involvement, autonomic dysfunction, CSF pleuocytosis and $9.61 \%$ mortality were recorded in our series.

\section{Funding: Nil, Conflict of interest: Nil Permission from IRB: Yes}

\section{References}

1. Yuki N, Hartung HP. Guillain-Barré syndrome. N Engl J Med. 2012 Jun 14;366(24):2294-304. doi: 10. 1056/NEJMra1114525.

2. Landry J.B. Note sur la paralysie aigue. Gaz Hebd Med Chir. 1859;6:472-474. Landry J.B. Note sur la paralysie aigue. Gaz Hebd Med Chir. 1859;6:486-488.

3. Osler W. The principles and practice of medicine: Designed for the use of practioners and students of medicine. New York; Appleton:1892.

4. Guillain G, Barry J, Strohl A. Sur un syndrome de radiculonevrite avec hyperalbuminose $\mathrm{du}$ liquid cephalo-rachidien sans reaction cellulaire. Remarques sur les caracteres cliniques et graphiques des reflexes tendineux. Bull Mem Soc Med Hop Paris. 1916; 40: 1462-70.

5. Haymaker WE, Kernohan JW. The Landry-GuillainBarry syndrome; a clinicopathologic report of 50 fatal cases and a critique of the literature. Medicine (Baltimore). 1949; 28(1); 59-141.

6. Asbury AK, Arnason BG, Adams RD. The inflammatory lesion in idiopathic polyneuritis. Its role in pathogenesis.Medicine (Baltimore)1969;48(3):173-215. 
7. Sudulagunta SR, Sodalagunta MB, Sepehrar M, Khorram H, Bangalore Raja SK, Kothandapani S, et al. Guillain-Barre Syndrome: clinical profile and management. Ger Med Sci 2015;13:Doc 16. Doi: $10.3205 / 000220$

8. Kalra V, Sankhyan N, Sharma S, Gulati S, Choudhry $\mathrm{R}$, Dhawan B. Outcome in childhood Guillain -Barre Syndrome. Indian J Pediatr 2009;76(8):795-799.

9. Winer JB. An update in Guillain- Barre syndrome. Autoimmuno disease 2014, Article ID 793024, 6 pages.http://dx.doi.org/10.1155/2014/793024.

10. Hadden RDM, Cornblath DR, Hughes RAC, Zielasek J, Hartnug HP, Toyka KV et al. Electrophysiological classification of Guillain-Barre syndrome: clinical association and outcome. Ann Neurol1998;44(5):780-788.Doi:10.1002/ana.410440512

11. Islam Z, Jacobs BC, van Belkum A, Mohammad $\mathrm{QD}$, Islam MB, Herbrink $\mathrm{P}$ et al. Axonal variant of Guillain-Barre syndrome associated with Campylobacter infection in Bangladesh. Neurology 2010; 74 (7):581-7. Doi:10.1212/WNL.0b013e318cff735.

12. Nachamkin I, Arzarte Barbosa P, Ung H, Lobato C, Gonzalez Rivera A,Rodriguez $\mathrm{P}$ et al. Patterns of Guillain-Barre syndrome in children: results from Mexican population. Neurology 2007;69(17):1665-71.

13. Lehmann HC, Hartnug HP, Kieseier BC, Hughes RAC. Guillain-Barre syndrome after exposure to influenza virus. Lancet Infect Dis 2010;10(9):64351.doi:10.1016/S1473-3099(10)70140-7

14. Dieleman J, Romio S, Johansen K, Weibel D, Bonhoeffer J, Sturkenboom M. Guillain-Barre syndrome and adjuvanted pandemic influenza A (H1N1) 2009 vaccine: multinational case-control study in Europe. BMJ 2011 July 12; 343:d3908. Doi: 10.1136/bmj.d3908.
15. Sharma G, Sood S, Sharma S. Seasonal, age \& gender variation of Guillain-Barre syndrome in a tertiary referral centre in India.Neuroscience \& Medicine 2013;4:23-28.

16. Hughes RA, Swan AV, Raphel JC, Annane D, van Koningsveld R, van Doorn PA. Immunotherapy for Guillain-Barre syndrome: a systematic review. Brain 2007 Sep;130(Pt 9):2245-57.

17. Chatterjee A, Barman A, Das KM, Mandal PK, Sarkar UK, Ballav A, Pal S. Rehabilitative outcome and its predictors in Guillain-Barre syndrome. IJPMR 2009;20(2):37-43.

18. Bairwa M, Rajput M, Sachdeva S. Modified Kuppuswamy's Socioeconimic scale: Social researcher should include updated income criteria, 2012. Indian J Community Med 2013;38(3):185-6. Doi: 10.4103/09700218.116358

19. Van der Linden V, da Paz JA, Casella EB, MarquesDias MJ. Guillain-Barre syndrome in children: clinical and epidemiological studyof 61 patients. Arq Neupsiquiatr 2010;68(1):12-17

20. Wu X, Shen D, Li T, Zhang B, Li C, Mao M, et al. Distinct Clinical Characteristics of Pediatric GuillainBarre syndrome: A Comparative Study between Children and Adults in Northeast China. PLos ONE 2016;11(3): e0151611.doi:1371/journal.pone.0151611.

21. Mathew T, Srinivas M, Nadig R, Arumugam R, Sarma GRK. Seasonal and monthly trends in the occurrence of Guillain-Barre syndrome over a 5-year period: A tertiary care hospital -based study from South India. Annals of Indian Academy of Neurology 2014;17(2):239-241

22. $\mathrm{Hu} \mathrm{MH}$, Chen $\mathrm{CM}$, Lin $\mathrm{KL}$, Wang HS, Hsia $\mathrm{SH}$, Chou ML, et al. Risk factors of Respiratory failure in children with Guillain-Barre syndrome. Pediatr Neonatol 2012;53(5):295-299. Doi:10.1016/j. pedneo. 2012.07.003.

\section{How to cite this article?}

Meshram R. M, Bokade C. M, Merchant S, Abhisheik S, Agrawal H, Dhakne S. Clinical profile of childhood GuillainBarre Syndrome. Int J Pediatr Res.2016;3(6):427-432.doi:10.17511/ijpr.2016.i06.10. 